\title{
Respiratory Exchange Ratio
}

National Cancer Institute

\section{Source}

National Cancer Institute. Respiratory Exchange Ratio. NCI Thesaurus. Code C123568.

The ratio of the amount of carbon dioxide produced to the amount of oxygen consumed in one breath. This ratio is used to estimate the respiratory quotient, which indicates what type of fuel source the body is metabolising to provide energy. 